\title{
LO SINIESTRO: MÁS ALLÁ DE FREUD
}

\author{
THE UNCANNY: BEYOND FREUD
}

Irene ACHÓN LEZAUN

Universidad San Jorge (Zaragoza)

iachon@usj.es

\begin{abstract}
[...] inclinándose hacia su boca, sus labios ardientes se encontraron con los labios helados de Olimpia. Apenas hubo tocado la fría mano de Olimpia, se sintió dominado por el terror y se le pasó por la mente la leyenda de la novia muerta, pero Olimpia le oprimía contra su pecho y el beso pareció vivificar sus labios...
\end{abstract}

E. T. A. Hoffmann, El hombre de la arena (1817)

$\mathrm{O}$ bjetos sin vida que de pronto aparecen animados; ${ }^{1}$ el crujir de la madera; esa muñeca que, estamos convencidos, hemos visto pestañear; los pasos rápidos que creemos oír por el pasillo, en mitad de la noche, cuando sabemos que no hay nadie más en casa: provocaciones de nuestra mente que pocas veces podemos evitar («No pienses en un elefante rosa»). El estrés, el cansancio o la sugestión pueden traer a nuestra imaginación los peores miedos; en otras ocasiones, nos acercamos voluntariamente a experiencias que nos suben las pulsaciones y nos aterran o incluso espantan: historias de muertos resucitados, cuerpos desmembrados, ${ }^{2}$ dobles malignos que aparecen, el enterramiento prematuro, leyendas en mitad del bosque... Pensar en cada una de estas cuestiones nos produce, cuando menos, cierto desasosiego. ¿Por qué, entonces, buscamos placer en fuentes de horror? ¿Por qué somos capaces de crear ficción a través de lo siniestro? Y, lo que resulta más perverso: ¿por qué disfrutamos como consumidores de ficción de lo siniestro no vivenciado? ¿Por qué seguimos acercándonos a aquello que nos provoca sensaciones, cuando menos, desagradables?, ¿por qué, como

\footnotetext{
111 «E. Jentsch destacó, como caso por excelencia de lo siniestro, la "duda de que un ser aparentemente animado, [sic] sea en efecto viviente; y a la inversa: de que un objeto sin vida esté en alguna forma animado"» (Freud, 1919: 18, en cursiva en el texto).

2 «Los miembros separados, una cabeza cortada, una mano desprendida de un brazo [...], pies que danzan solos [...]: son cosas que tienen algo sumamente siniestro, especialmente si [...] conservan una actividad independiente» (Freud, 1919: 29).
} 
en «La casa cerrada» de Marcel Schwob ${ }^{3}$ nos detenemos a contemplar lo que nos desagrada o nos aterra en vez de salir corriendo?

Será oportuno enunciar aquí dos formulaciones en las cuales quisiera condensar lo esencia de nuestro pequeño estudio [sobre lo siniestro]. Ante todo: si la teoría psicoanalítica tiene razón al afirmar que todo afecto de un impulso emocional, cualquiera que sea su naturaleza, es convertido por la represión en angustia, entonces es preciso que entre las formas de lo angustioso exista un grupo en el cual se pueda reconocer que esto, lo angustioso, es algo reprimido que retorna. Esta forma de la angustia sería precisamente lo siniestro, siendo entonces indiferente si ya tenía en su origen ese carácter angustioso, o si fue portado por otro tono afectivo. En segundo lugar, si esta es realmente la esencia de lo siniestro, entonces comprenderemos que el lenguaje corriente pase insensiblemente de lo «Heimlich» a su contrario, lo «Unheimlich», pues esto último, lo siniestro, no sería realmente nada nuevo, sino más bien algo que siempre fue familiar a la vida psíquica y que solo se tornó extraño mediante el proceso de su represión. Y este vínculo con la represión nos ilumina ahora la definición de Schelling, según la cual lo siniestro sería algo que, debiendo haber quedado oculto, se ha manifestado. (Freud, 1919: 27-28, en cursiva en el texto) ${ }^{4}$

Freud recoge en su estudio (1919) sobre lo siniestro qué es el término y lo que lo provoca (como los objetos sin vida animados, el doble, el retorno involuntario a un lugar, los presentimientos y el mal de ojo, o la muerte) ${ }^{5}$ sin embargo, cuando nos adentramos en el sentimiento de lo siniestro cabe preguntarse también por qué lo buscamos, qué esperamos encontrar u ocultar cuando seguimos contemplando aquello que nos espanta (tanto en la vida real como en la ficción), y aquí es cuando nos topamos con la verdad que no queremos que salga a la luz, con la negación: de alguna manera, nos avergüenza. Sigue siendo, por lo tanto, necesario investigar el sentimiento y abrir más el camino hacia la duda que genera sobre su disfrute.

Hay ciertos temas de interés absorbente, pero demasiado horribles para ser objeto de una obra de ficción. El mero escritor romántico debe evitarlos si no desea ofender o desagradar. Solo se los usa con propiedad cuando lo severo y lo majestuoso de la verdad los santifican y los sostienen. Nos estremecemos con el más intenso de los «dolores agradables» ante los relatos del paso de Beresina, del terremoto de Lisboa, de la peste de Londres y de la matanza de San Bartolomé, o la asfixia de los ciento veintitrés prisioneros en el Pozo Negro de Calcuta. Pero en estos relatos lo excitante es el hecho, la realidad, la historia. Como invenciones nos inspirarían simple aversión. (Poe, 1953: I, 197)

Lo ominoso, lo sublime, lo bello según se mire, lo asqueroso, lo amoral... son demasiados los conceptos que se acercan a lo siniestro o, incluso, dependen de él. Cualquiera, no obstante, sabe usar el término siniestro, pues, al final, no es más que aquello que, de alguna manera, nos produce un escalofrío, aquella persona que, viéndola simpática, nos parece que algo oculta, aquel presagio de que algo va a pasar. Porque sabemos que la perfección no existe y cuando la tenemos delante sentimos que

\footnotetext{
3 «Así que la casa cerrada nos asustaba, sin saber por qué. Una noche nos paramos delante de ella. Dese la distancia del bordillo de la acera podíamos oír con claridad una respiración fuerte, regular y continua, que parecía surgir de sus muros. Era como si un colosal durmiente estuviera acostado al otro lado de la pared. Permanecimos así, escuchando su respiración, durante más de una hora» (Schwob, 1893: 73).

${ }^{4}$ Freud, al hablar de la «definición de Schelling», se refiere a lo que recoge unas páginas antes en su estudio: «[...] nos llama la atención una nota de Schelling que enuncia algo completamente nuevo e inesperado sobre el contenido del concepto unheimilich: Unheimlich sería todo lo que debía haber quedado oculto, secreto, pero que se ha manifestado» (1919: 17, en cursiva en el texto).

${ }^{5}$ No deja de resultar curioso que las escasas veinte páginas del texto del psicoanalista (1919) sigan hoy como referente para iniciarse en el tema.
} 
algo esconde. Desde ese «No me da buena espina» 0 «ni un duro de confianza» hasta el «iQué horror!», hay muchas paradas; sin embargo, todos podemos señalar qué es aquello que despierta en nosotros el sentimiento de lo siniestro, lo que no nos es familiar, lo que nos genera desconfianza.

Lo que se pretende, con este monográfico de Tropelías, es profundizar en el término siniestro e indagar, un poco más, en por qué seguimos acercándonos a lo que lo provoca, por qué nos llama la atención y qué mueve en nosotros. Qué esperamos encontrar y, también, qué pretendemos ocultar, qué pretendemos encerrar cuando, de manera voluntaria, nos sometemos a sus efectos: ¿en qué nos ayuda lo siniestro?, ¿hace que, de alguna manera, desfoguemos nuestra parte oscura?

$\mathrm{Si}$ «siniestro» es todo aquello que no debería haber salido a la luz, ¿nos referimos a nuestro interior? Cuando hablamos de «terror» o de «miedos», pensamos siempre en agresiones externas: fantasmas, asesinos, terremotos. Da igual que el miedo sea real o metafísico, según la clasificación de Roas; ${ }^{6}$ pocas veces pensamos en personajes como Jack Torrance en El resplandor, ${ }^{7}$ es decir, pocas veces nos miramos al espejo y como un agente Cooper $^{8}$ enloquecido nos vemos como amenazas; pero, realmente, cuando hablamos de siniestro como algo que no debería salir a la luz, no debemos pensar solo en aquello que puede venir de fuera, sino en lo que podemos llevar dentro.

Produce, pues, el sentimiento de lo siniestro la realización de un deseo escondido, íntimo y prohibido. Siniestro es un deseo entretenido en la fantasía inconsciente que comparece en lo real; es la verificación de una fantasía formulada como deseo, si bien temida. En el intersticio entre ese deseo y ese temor se cobija lo siniestro potencial, que al efectuarse se torna siniestro efectivo. Lo fantástico encarnado: tal podría ser la fórmula definitoria de lo siniestro. (Trías, 1982: 48)

Ya lo sublime nos trajo de la mano el pleasing horror como concepto que desmontaba nuestra moral, que nos hacía enrojecer y reconocer que disfrutábamos de lo que aparentemente no era bello; sin embargo, una vez superado el trauma, nos falta escarbar más en nuestra vergüenza y entender por qué disfrutamos con lo siniestro. Lo que nos inquieta, nos incomoda, pero nos atrae.

¿Sabía el Nathaniel de El hombre de la arena que Olympia era una autómata? ¿Lo sabía y eso le hizo sentir más atracción? Resulta interesante cómo lo siniestro está presente en la tradición popular camuflado de tal manera que a los receptores les ofendería si les dijéramos que disfrutan con ello. En Blancanieves, por ejemplo, el príncipe al final acaba besando un cadáver, algo que, dicho así, repugna; sin embargo, la oratoria ha conseguido plasmar en esa escena el amor romántico. ${ }^{9}$

¿La belleza es a veces siniestra o lo siniestro nos resulta bello?, ¿qué hay del horror placentero? Freud analizó lo que nos provoca esa sensación de extrañeza, aquel Unheimlich, pero aún nos falta

\footnotetext{
${ }^{6}$ David Roas habla de la diferencia entre el «miedo físico (o emocional)», que sería el que «tiene que ver con la amenaza física, la muerte y lo materialmente espantoso» (2011: 95, en cursiva en el texto), y el «miedo metafísico (o intelectual), que es «la impresión propia y exclusiva de lo fantástico [...], que se produce cuando nuestras convicciones sobre lo real dejan de funcionar, cuando perdemos pie frente a un mundo que antes nos era familiar» (2011, 95-96, en cursiva en el texto).

${ }^{7}$ Interpretado por Jack Nicholson en la película de Stanley Kubrick (The Shining, 1980).

${ }^{8}$ Dale Copper (interpretado por Kyle MacLachlan), Twin Peaks, Mark Frost y David Lynch, (1990-1991).

9 Freud ya nombró este caso en su ensayo: «Hemos visto que la catalepsia y la resurrección de los muertos son representaciones siniestras [...]. ¿Quién osaría decir que es siniestro ver cómo, por ejemplo, Blanca Nieves abre los ojos en su ataúd?» (1919: 31).
} 
recorrido para entender por qué. ¿Es un artificio del lenguaje (escritura y audiovisual) que nos hace apartar lo desagradable y horroroso y transformar lo siniestro en algo placentero (morboso), algo subliminal?; o, realmente, ¿sabemos en nuestro foro interno que estamos percibiendo lo siniestro y, aun así, gozamos con ello?

Como si de acercarse a lo prohibido sin riesgo se tratara, la contemplación de lo siniestro nos pone más cerca de la parte de nuestro yo que no podemos (o, más bien, «debemos») dejar salir, es una manera de dar rienda suelta a esa parte oscura de nosotros, sin invadir la sociedad ni romper las normas morales: «El arte es fetichista: se sitúa en el vértigo de una posición del sujeto en que "a punto está" de ver aquello que no puede ser visto» (Trías, 1982: 54). ¿Sería, por lo tanto, el mundo un lugar peor sin lo siniestro? Un lugar lleno de monstruos libres (o liberados). Quizá lo sabemos y quizá por eso seguimos manifestando abiertamente el sentimiento, emisor y receptor, en el arte que, aunque algo inconcebible para algunas personas, no entiende de moral.

En este monográfico se pretende analizar cómo el arte a través de la ficción ha tratado de desentramar lo siniestro como fuente del horror placentero, cómo y por qué lo ominoso y lo sublime son fuentes de horror. Será verdad aquello que leemos en Trías: «Puede afirmarse, por tanto, que una de las condiciones estéticas que hace que una obra sea bella es su capacidad por revelar y a la vez esconder algo siniestro» (1982: 80).

Con la liberación de los sentidos tras la ruptura de lo correcto con la llegada del Romanticismo, las leyendas de brujas, fantasmas y los espacios terroríficos saltaron a la literatura donde encontraron el refugio de las antorchas que la sociedad racionalista perseguía: fuera las supercherías, arriba la ciencia. Ocurre que estas acertadas ideas no tenían en cuenta que los espíritus morbosos necesitan alimento, así que las letras de finales del XVIII y el XIX se llenaron con aquellas leyendas e historias macabras que en la sociedad ya no tenían cabida: fueron el alimento de la ficción para satisfacer las mentes que querían seguir sintiendo el escalofrío, pero, esta vez, desde la cómoda posición frente al calor de un hogar, sabiendo que estaban a salvo mientras leían las historias que les dejarían sin dormir durante la noche.

Como la adrenalina conseguida «artificialmente» en una montaña rusa, lo siniestro nos sirve para experimentar el dolor sin necesidad de sufrirlo. Lo malo, lo feo, lo oscuro pueden estar cerca sin suponer una amenaza para nosotros, o para los demás. ¿Somos observadores o ejecutores fantasma?

Los quince trabajos que siguen a este prólogo dan muestra de cómo y qué es lo siniestro y de cómo y por qué sentimos curiosidad por aquello y, más allá, por qué lo creamos y lo disfrutamos. Tania Alba Rios y Sara Molpeceres con los dos primeros artículos hacen un recorrido por los orígenes del término que sirven, desde luego, como excelente base para aquellos que se acerquen al concepto por primera vez.

María López Villarquide nos trae un clásico, como es Giselle y la puesta en escena de Akram Khan: como espectadores nos sentiremos más incómodos, pero más atados a la obra, cuanto más seamos capaces de identificarnos con ella (aunque esto, evidentemente, nos produzca cierto temor). 
La literatura ha sido, quizá, una de las artes más estudiadas dentro de lo siniestro; sin embargo, no dejan de aparecer análisis que plantean nuevas cuestiones. Porque a veces lo siniestro viene de donde menos lo esperamos y lo perturbador puede aparecer donde no creeríamos -incluso en textos con una mezcla de humor y erotismo-, Juan Trouillhet analiza Un maestro de las sensaciones de Andrés Ibáñez.

¿Es posible gozar con lo siniestro? Verónica Murillo-Chinchilla analiza esta cuestión en los cuentos de Silvina Ocampo, donde los personajes, aun inmersos en situaciones siniestras, se dejan llevar e, incluso, participan con cierto disfrute sin que por ello se genere un conflicto interior.

Es también en la literatura donde tenemos múltiples ejemplos de cómo la mujer ha sido tachada de personaje malvado y objeto, y de cómo el deseo de dominación del hombre a la mujer y el deseo de tenerla como propiedad han sido alimentados por el imaginario colectivo que ha normalizado el rapto, la violación y el asesinato de mujeres. Sylvia Lenaers Cases y Andrea Abalia Marijuán destapan en sus artículos este trato que la mujer recibe en la ficción no solo como objeto de deseo y de posesión, sino como foco de las más oscuras perversiones. La obsesión por los cadáveres femeninos que ya teníamos en Poe, que se ve en pinturas clásicas, y en los más recientes productos artísticos ${ }^{10}$ son solo algunos ejemplos de cómo - como nos dirá Sylvia Lenaers - lo siniestro es una excusa para convertir en ordinario lo sobrecogedor.

Si hemos dicho que en el arte es donde damos rienda suelta a nuestras emociones y pasiones más oscuras, en el trato a la mujer dentro de la literatura tenemos la base para denunciar la misoginia latente aún en nuestros días. Figuras de cera, muñecas y otras formas de dominar a la mujer. Presentada, cuando tiene personalidad, como un personaje como la femme fatale es uno de los temas abordados, junto a los científicos locos, los dobles y las mutilaciones, por Lourdes Santamaría Blasco en un artículo que nos sirve como salto de lo textual a lo audiovisual.

Y si teníamos un recorrido al principio del monográfico por el término siniestro con los artículos de Tania Alba Rios y de Sara Molpeceres, en el texto de Javier Hernández encontramos sin duda un repaso por el surgimiento de lo gótico en el cine, fruto de la novela gótica y la pintura romántica, de las que bebe por lo narrativo y por lo visual, sin perder esa ruptura de esquemas que supuso la estética romántica con su definición de lo bello hacia el concepto de lo siniestro.

Siguiendo con lo audiovisual, Silvia Guillamón Carrasco y Jorge Belmonte Arocha analizan en su artículo esa parte más oculta que tenemos y que ha trabajado el psicoanálisis atendiendo a cuestiones como la fantasía, la represión o el inconsciente en la representación de lo siniestro que tenemos en Parents (Bob Balaban, 1989), cómo se representa lo íntimo, escondido y prohibido en esta comedia de terror que a través de la sátira utiliza lo siniestro para hablar de las fantasías y deseos ocultos que pueden ser metáfora de lo que somos.

Y como una metáfora poética y visual se nos presenta la serie Chernobyl en muchas ocasiones, con un manejo de lo visual medido en encuadres, con imágenes oníricas, preciosistas, que esconden el horror vivido, camuflan el espanto, tras un accidente nuclear. Porque lo cotidiano puede tornarse

\footnotetext{
${ }^{10}$ Como el cadáver de Laura Palmer (Twin Peaks, Mark Frost y David Lynch, [1990-1991]).
} 
espantoso y lo real supera a la ficción, Basilio Casanova Varela explora la intimidad y lo familiar (Heimlich) en las imágenes de la serie de HBO. En este artículo vemos la presencia lo Unheimlich en la intimidad de lo doméstico o familiar: el surgir de lo siniestro u ominoso en los espacios reservados a lo privado. De lo doméstico al horror no hay más que un paso: lo familiar, lo conocido, que de pronto se vuelve espantoso. Lo cotidiano que se hace irreconocible: el ser humano comete errores y toma decisiones equivocadas; sin embargo, cuando observamos los errores, la negación de la responsabilidad, o la ausencia de conciencia, cabe preguntarse si ser humano es algo que llevamos intrínseco como seres humanos: ¿qué características se deben cumplir para ser humano? ¿Qué nos hace humanos?

De la condición humana nos habla Helena Tur Planells con su estudio dirigido por el pensamiento de Heidegger, tratando el tema del cíborg y su no lugar en la humanidad. Lo siniestro nos afecta de maneras diferentes dependiendo del individuo; sin embargo, al margen de la experiencia que cada ser pueda sufrir de manera particular, lo que lo hace universal es su propia condición de sensación. Tur Planells pone sobre la mesa el tema de los sentimientos y las emociones, relacionados con la adquisición de conciencia, empujándonos a cuestionarnos si son los sentimientos, y las emociones, junto a la idea de pertenencia al mundo lo que nos define como humanos.

Puede unirse esta reflexión con el texto de Mario de los Santos Aparicio: un análisis termodinámico de las emociones básicas de los seres humanos y de los géneros narrativos confluyendo en el estado termodinámico de lo siniestro. Presentado dentro del marco de la hermenéutica filológica y la antropología lingüística, encontramos en sus líneas una aproximación al término emoción, lo que nos llevará a la emoción central del texto, lo siniestro, pasando por un análisis de las variaciones energéticas subjetivas que encontramos ante determinadas emociones.

Y acercándonos más a lo experimental, Javier Calvo Anoro plantea el estudio de lo siniestro en los videojuegos. En este campo se explora la narración, pero sin olvidar que, siendo un producto audiovisual, el videojuego va más allá de la relación entre pantalla y espectador que plantean los productos televisivos y fílmicos: propone una experiencia donde el usuario ya no es un mero receptor de información, sino que puede participar en la narración y experimentar de una manera más interactiva emociones como el miedo.

Lo siniestro nos sirve para experimentar el dolor sin necesidad de sentirlo, sin pasarlo mal, pero cuanto más cercano a la realidad lo percibimos más nos puede desagradar a la vez que atraer. A veces la violencia en la ficción nos parece excesiva, nos resulta desagradable plantarnos ante una agresividad en el arte que nos espanta, aunque, por otro lado, como hemos visto, la buscamos incluso en experiencias lo más cercanas a la realidad. Ana Isabel Cajiao Nieto analiza la representación de una realidad, como es el conflicto armado colombiano, la postura adoptada por diferentes artistas a la hora de plasmar un horror de este mundo. Como espectadores, esta vez pasivos, nos situamos ante la incongruencia: disfrutamos contemplando mientras nos recorre un sentimiento de desasosiego. Lo explícito nos aterra, nos hace retirar la mirada en muchas ocasiones mientras que lo que no vemos, lo que queda oculto y solo podemos intuir, nos llama la atención. 
Hacemos, pues, un repaso en este monográfico por las artes escénicas, la pintura, el fotoperiodismo, la literatura, lo audiovisual, los videojuegos y la termodinámica. Las intertextualidades que encontramos entre textos y otros productos de diferentes épocas no dejan de ser una muestra de que Freud con sus antecesores instauró unas bases sobre las que seguir construyendo a nivel de consumo (creadores y receptores) y a nivel analítico: ¿es aquello morboso?, ¿podemos etiquetar algo como «oscuro» cuando puede ser de una belleza tétrica? ¿Quién decide qué es bello y qué no lo es? ¿Por qué nos atrae aquello que debería mantenernos lejos? ¿Es aquello siniestro o somos nosotros los siniestros?

Las respuestas a estas preguntas no son, ni mucho menos, sencillas, ni pretendemos dar por cerrado el tema: tan solo, y con humildad, queremos seguir trabajando las líneas que marcaron los clásicos, pero demostrando cómo incluso en las plataformas de ocio más actuales lo siniestro sigue siendo atrayente. Quizá la termodinámica nos ayude a entender más el término, quizá nos ayude a entendernos. Mientras tanto, esperamos que quien sea conocedor del escalofrío, y quiera seguir alimentando la curiosidad, disfrute de este monográfico.

Deseo cerrar este prólogo agradeciendo a todas las autoras y todos los autores su trabajo y, por supuesto, a la revista Tropelías, el espacio necesario para que lo oculto salga a la luz.

\section{Referencias bibliográficas}

Freud, Sigmund (1919): Lo siniestro. Trad. de Luis López Ballesteros y de Torres, en E. T. A. Hoffmann, El hombre de la arena, pp. 9-35.

Hoffmann, E. T. A (1817): El hombre de la arena. Trad. de Carmen Bravo-Villasante. José J. de Olañeta (ed.). Barcelona: El Barquero. [2008].

PoE, Edgar Allan (1953): «El entierro prematuro», en Cuentos i. Trad. de Julio Cortázar. Alianza Editorial: Madrid. [2006].

ROAS, David (2011): Tras los límites de lo real. Una definición de lo fantástico, Páginas de Espuma: Madrid.

SchwoB, Marcel (1893): «La casa cerrada», en Mundos terribles. Trad. Eric Jalain. El Olivo Azul: Sevilla. [2007].

TRÍAS, Eugenio (1982): Lo bello y lo siniestro. Seix Barral: Barcelona. [2018]. 